\title{
Clinical Presentation and Management of Endometriosis-Related Hemorrhagic Ascites: A Case Report and Systematic Review of the Literature
}

\author{
Mareesol Chan-Tiopianco ${ }^{1,2}$, Wei-Ting Chao ${ }^{3}$, Patrick R. Ching ${ }^{4}$, Ling-Yu Jiang ${ }^{3,5}$, Peng-Hui Wang ${ }^{3,5}$, \\ Yi-Jen Chen ${ }^{3,5}$ \\ 1. Division of Obstetrics and Gynecology, San Lazaro Hospital, Manila, PHL 2. Department of Obstetrics and \\ Gynecology, ManilaMed - Medical Center Manila, Manila, PHL 3. Department of Obstetrics and Gynecology, Taipei \\ Veterans General Hospital, Taipei, TWN 4. Department of Medicine, University of Maryland Medical Center Midtown \\ Campus, Baltimore, USA 5. Institute of Clinical Medicine, National Yang-Ming University, Taipei, TWN
}

Corresponding author: Yi-Jen Chen, chenyi@vghtpe.gov.tw

\begin{abstract}
This study aims to analyze the patient profile and presentation of endometriosis-related hemorrhagic ascites and review its management to raise awareness among gynecologists and improve treatment strategies. We present a case report and engage in a systematic review involving human cases of histologically proven endometriosis with hemorrhagic ascites. Keywords were searched in PubMed/MEDLINE, Cochrane Library, EMBASE, and Ovid Discovery databases from inception until December 2018. Studies that did not include a description of ascites or histopathologic results confirming endometriosis or those that involved patients with other conditions that may contribute to ascites were excluded.
\end{abstract}

The review yielded 73 articles describing 84 premenopausal women with histologically proven endometriosis-related hemorrhagic ascites. Of note, $83 \%$ (65/78) of the patients were nulliparous and 69.35\% (43/62) were of African descent. The most common chief complaint was abdominal enlargement $(58.33 \%, 49 / 84)$ but a host of other symptoms were also reported. Pleural effusion was reported in $32.14 \%$ (27/84), and elevated CA-125 was seen in $74.42 \%$ (32/43). The majority $(64.29 \%, 54 / 84)$ of the patients underwent laparotomy, and an increasing trend of minimally invasive surgical approaches $(p<0.001)$ and fertility-sparing techniques ( $\mathrm{p}<0.001)$ was observed. The mean ascites volume was $4228.27 \mathrm{~mL}$ (SD: 2625.66). Moderate to severe endometriosis was seen in $97.44 \%$ (76/78) of cases. The majority of the patients who received medical treatment were given gonadotropin-releasing hormone $(\mathrm{GnRH})$ agonists $(63.79 \%$, $37 / 58)$. The rate of recurrence after termination or suppression of ovarian function was $8.33 \%(7 / 84)$, and there was a mortality rate of $1.19 \%(1 / 84)$. Diagnosis of endometriosis-related hemorrhagic ascites may be challenging because it mimics several disease entities that cause ascites, thereby warranting a heightened clinical suspicion. Minimally invasive techniques are usually employed to establish a histologic diagnosis. The prevention of recurrence involves the recognition of endometriosis-related hemorrhagic ascites as a manifestation of severe endometriosis, which should prompt therapies directed at suppressing ovarian function. Since affected women are of childbearing age, ovary-preserving surgeries are generally preferred. The rate of recurrence is low after appropriate surgical and medical interventions.

\section{Introduction}

Hemorrhagic ascites is a rare complication of endometriosis. The first description of endometriosis-related ascites has been attributed to Brews in 1954 [1]. However, it was not until 1957 that Charles first chronicled a case of blood-stained ascites in association with endometriosis [2]. Since then, fewer than 100 reports of hemorrhagic ascites related to endometriosis have been published in the literature.

Endometriosis-related hemorrhagic ascites may manifest with varying symptoms. Recognizing it may be difficult as it may present with similar disease processes such as malignancy, infection, cirrhosis, or trauma [3-6]. In light of this, we conducted this study to examine and elucidate the patient profiles and presentation of the disease to raise clinical awareness among gynecologists regarding the diagnosis of hemorrhagic ascites associated with endometriosis.

\section{Case Presentation}

A 34-year-old Taiwanese nulligravida woman presented to the outpatient department with a one-year history of irregular dysmenorrhea that was $5 / 10$ in severity. She had no other associated complaints such as 


\section{Cureus}

weight loss, anorexia, dyspareunia, urinary changes, or heavy menstrual bleeding. On further probing, the patient revealed having mild bloating that did not cause discomfort. Her menstruation occurred at regular monthly intervals. On physical examination, she had clear breath sounds and mildly distended flanks. Pelvic examination showed a corpus enlarged to 8-10 weeks' size without adnexal masses or tenderness. Fullness at the cul-de-sac was palpated. Pelvic ultrasound revealed multiple small leiomyomas with massive ascites and a heterogeneous right ovarian tumor. A CT scan showed a multicystic right ovary with soft tissue seeding to bilateral paracolic gutters, omentum, and recto-uterine pouch, with massive ascites (Figures 1, 2). CA-125 was elevated $(819.1 \mathrm{U} / \mathrm{mL})$. With the working diagnosis of a possible malignant ovarian tumor, laparotomy was performed with staging surgery in mind.

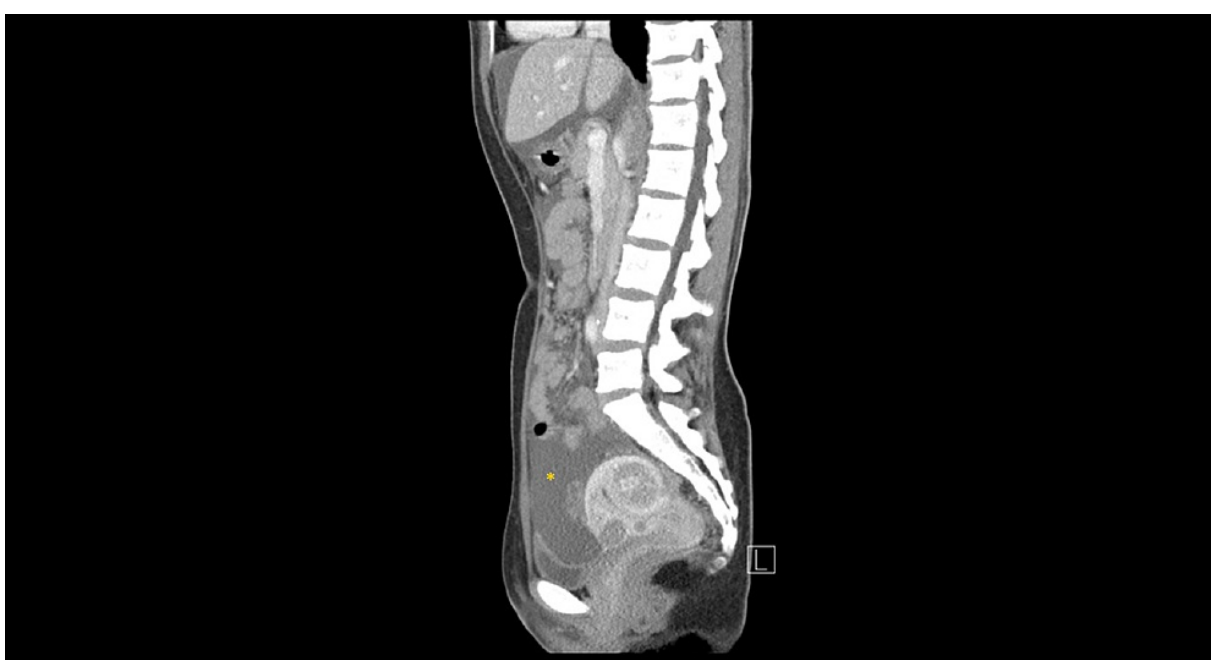

FIGURE 1: Abdominal CT scan - sagittal view showing massive ascites (asterisk)

CT: computed tomography

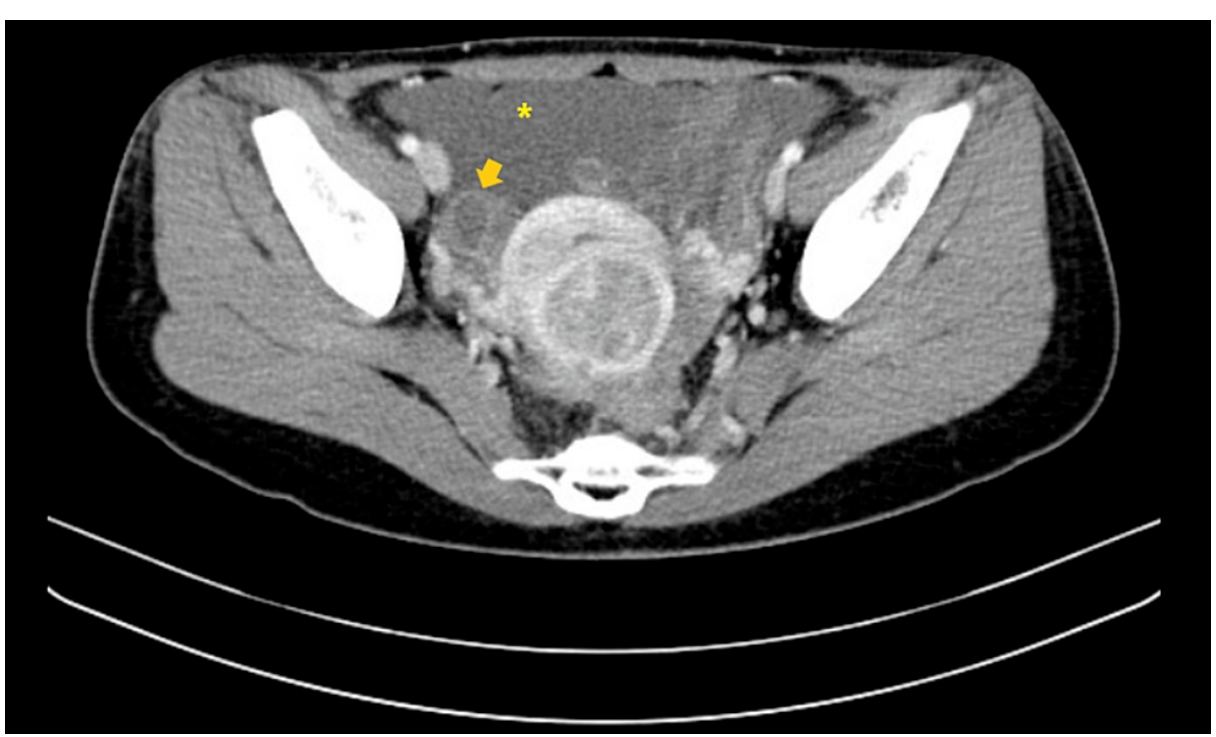

FIGURE 2: Abdominal CT scan - axial view showing massive ascites (asterisk), right adnexal mass (arrow), and soft tissue seeding

CT: computed tomography

Intraoperatively, 2 liters of dark-red ascitic fluid was drained (Figure $3 a$ ). Both adnexa were plastered to the posterior uterine wall. An ovarian tumor could not be identified. Friable soft tissue lesions were found on the uterine surface (Figure $3 b$ ). The cul-de-sac was obliterated. Multiple gray soft tissue nodules were scattered about the contracted omentum, mesentery, and the appendix (Figures $3 c, 3 d$ ). Minimal manipulation of the pelvic organs provoked bleeding. The frozen section and final histopathological report of the implants were 


\section{Cureus}

consistent with endometriosis. A diagnosis of stage IV endometriosis was made.

The patient had an uncomplicated postoperative course and was started on leuprorelin injections once a month for six months. After two months, a repeat ultrasound showed mild ascites $(\sim 100 \mathrm{~mL})$. The patient remained otherwise asymptomatic on her monthly follow-up visits.

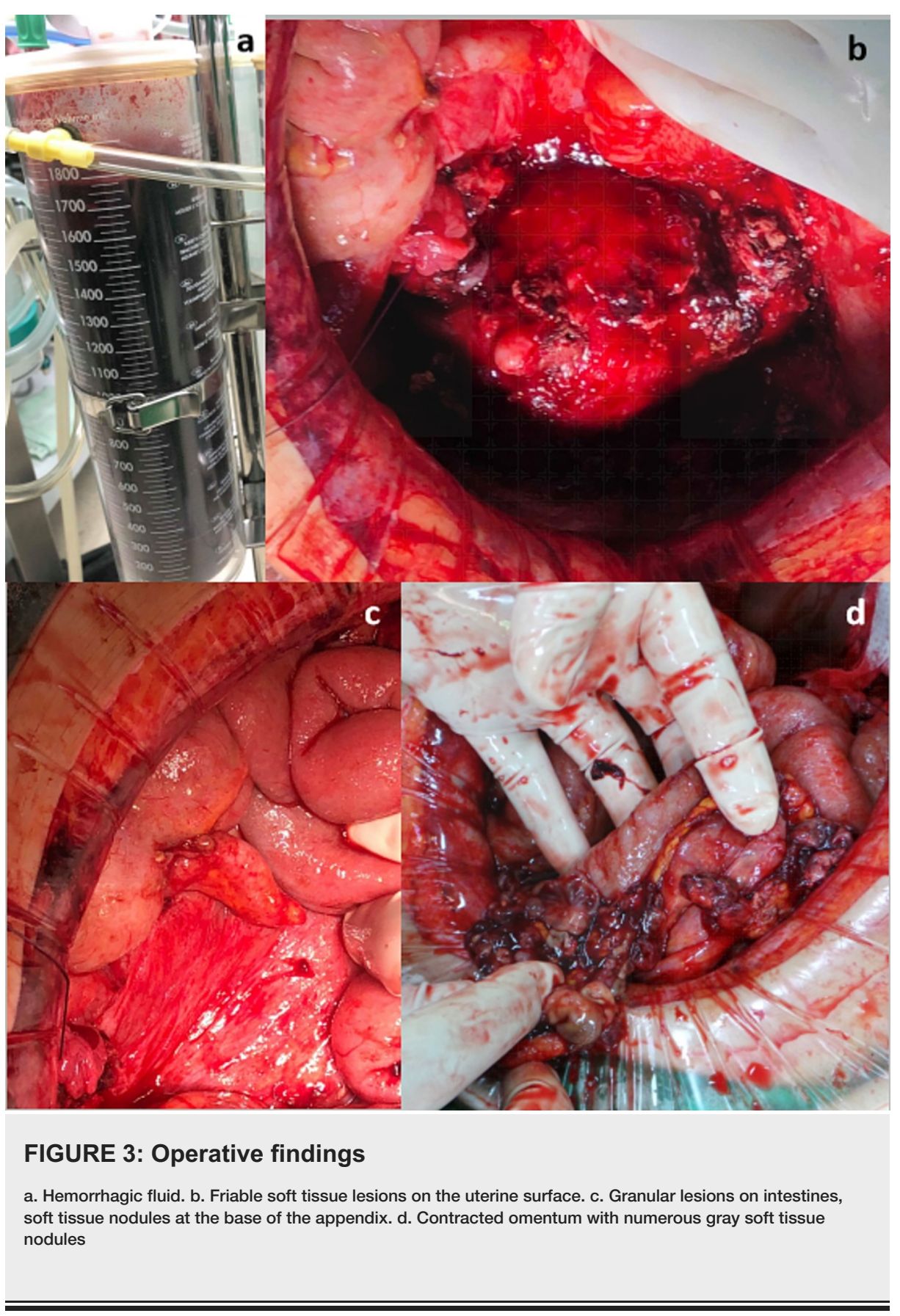

\section{Discussion}

\section{Methods}

Literature Search Strategy

An extensive literature search of all case reports, case series, and letters to the editor was performed. PubMed/MEDLINE, Cochrane Library, EMBASE, and Ovid Discovery were searched with the keywords, "endometriosis" OR "endometriotic "OR "endometrioma" AND "ascites" OR "bloody ascites" OR

"hemorrhagic ascites" OR "serosanguinous "OR "chocolate" OR "brown fluid" OR "chocolate ascites" OR "brown ascites" OR "serosanguinous ascites". Human studies involving women with biopsy-proven endometriosis published in any language were included, from inception until December 2018. 


\section{Cureus}

Eligibility Criteria

Studies with no available full-texts, non-histologically proven cases of endometriosis, non-hemorrhagic ascites, or those without a description of ascites were excluded. Patients with conditions that may cause ascites or hemorrhage (current tuberculosis, malignancy, other infections, ovulation induction, end-stage renal disease, HIV), history of trauma, pregnancy, were likewise excluded.

Screening and Data Extraction

Two independent reviewers (MCT and WTC) reviewed all titles and abstracts of articles obtained through the online database search. The full-text articles of abstracts that were deemed relevant were retrieved online or by manual searching. Reviewed articles were entered into a standardized data collection matrix. Information on authors, country/continent of origin, year of publication, patient characteristics such as age, parity, and ethnicity were entered into the data matrix. Chief complaint, character and volume of the ascites, interventions, intraoperative findings, severity of endometriosis, and outcomes were likewise recorded. In cases where the exact volume of ascites was not stated in a study, ascites was quantified based on the definitions from the existing literature and consensus reports [7-9]. The severity of endometriosis was recorded in each case or assessed based on intraoperative descriptions vis-a-vis the revised American Society for Reproductive Medicine (ASRM) classification of endometriosis [10].

\section{Quality Assessment of Case Reports}

MCT and WTC independently assessed the quality of individual studies based on the checklist for case reports and case series from the Joanna Briggs Institute Critical Appraisal tools for systematic reviews [11].

PRISMA Flow Diagram

The literature search strategy was summarized in a flow diagram based on the protocol laid out by the Preferred Reporting Items for Systematic Reviews and Meta-analyses (PRISMA) Statement [12] (Figure 4).

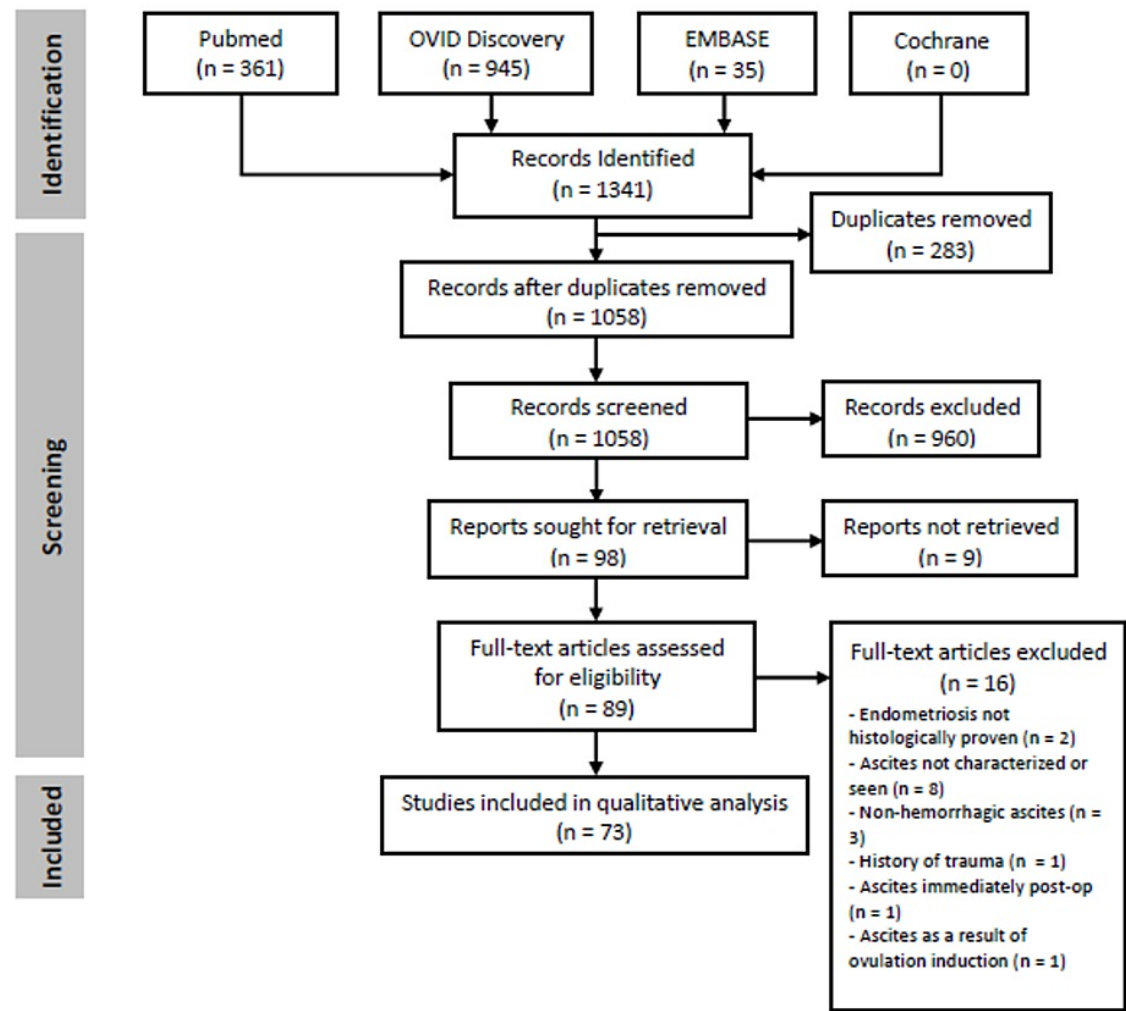

FIGURE 4: PRISMA flow diagram

PRISMA: Preferred Reporting Items for Systematic Reviews and Meta-analyses

Statistical Analysis 


\section{Cureus}

Descriptive statistics were used to report study and patient characteristics, including symptoms and peritoneal involvement. Spearman rank correlation was used. Analyses were done using the Stata software version 16.0 (StataCorp, College Station, TX).

\section{Results}

The literature search initially yielded 1,341 citations for review. After a screening based on the inclusion and exclusion criteria, 73 case reports involving 84 women of endometriosis-related hemorrhagic ascites were included in the final analysis. These were published from 1957 to 2018. The patient demographics, clinical presentation, and management as described in these reports are summarized in Table 1.

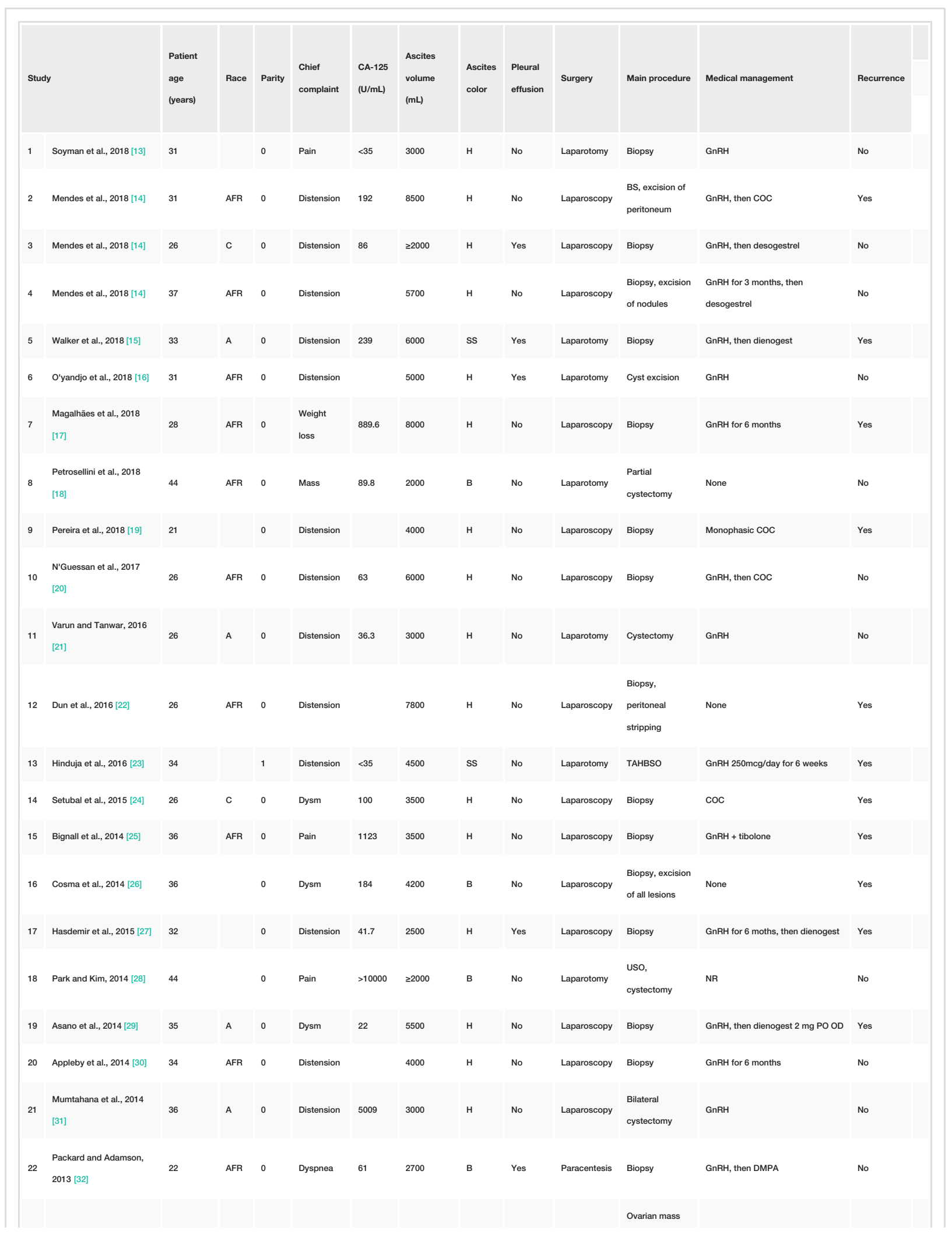




\section{Cureus}

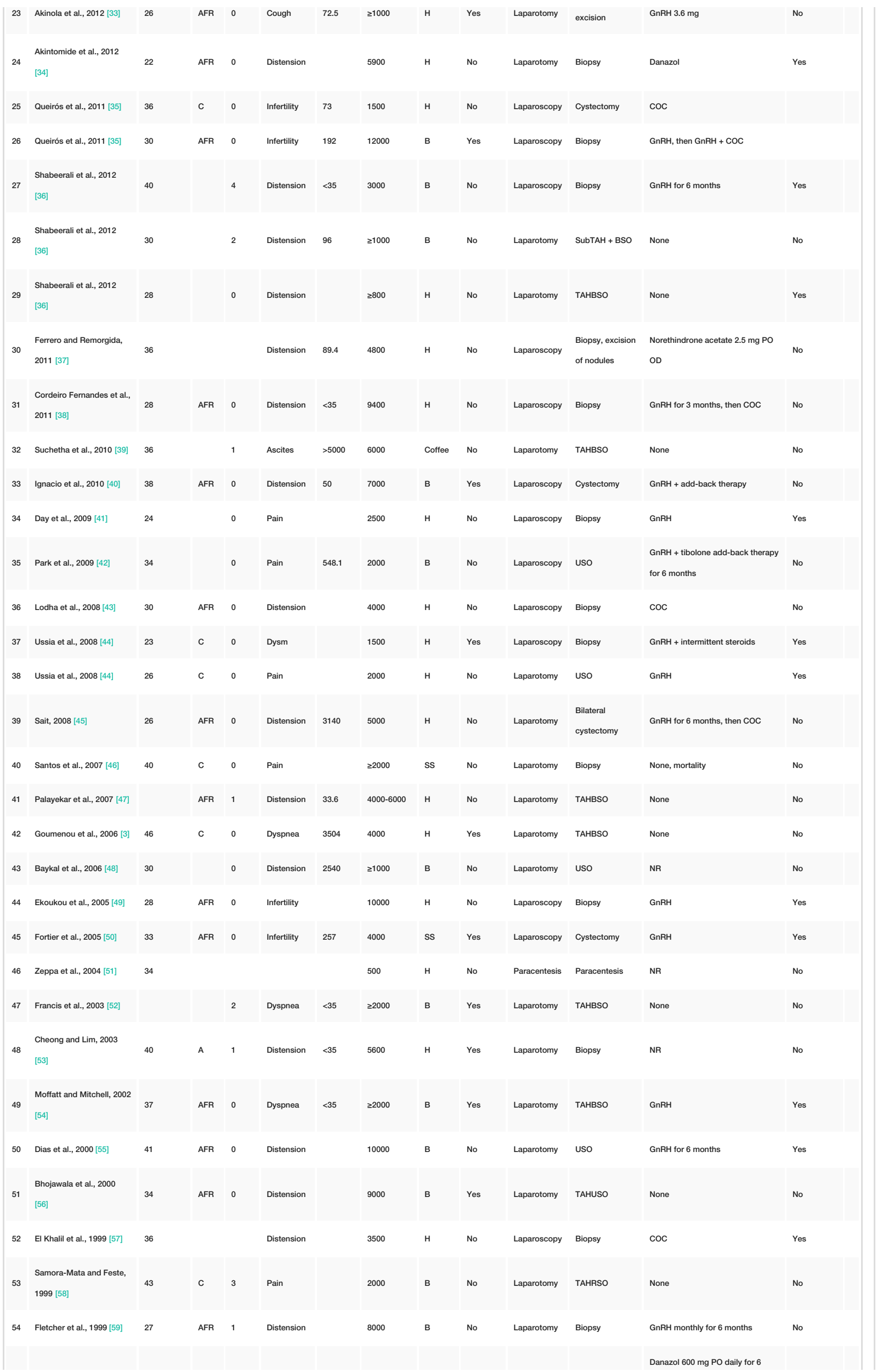




\section{Cureus}

\begin{tabular}{|c|c|c|c|c|c|c|c|c|c|c|c|c|c|}
\hline 55 & $\begin{array}{l}\text { Muneyyirci-Delale et al., } \\
1998[60]\end{array}$ & 26 & AFR & & Pain & 455 & 2000 & $\mathrm{H}$ & Yes & Laparotomy & $\begin{array}{l}\text { Bilateral } \\
\text { cystectomy }\end{array}$ & $\begin{array}{l}\text { months, then norethindrone } \\
\text { acetate }\end{array}$ & Yes \\
\hline 56 & $\begin{array}{l}\text { Muneyyirci-Delale et al., } \\
1998[60]\end{array}$ & 31 & AFR & 0 & $\begin{array}{l}\text { Shortness } \\
\text { of breath }\end{array}$ & & 10000 & B & Yes & Laparotomy & TAHBSO & None & Yes \\
\hline 57 & $\begin{array}{l}\text { Muneyyirci-Delale et al., } \\
1998[60]\end{array}$ & 32 & AFR & 0 & Distension & & 4900 & $\mathrm{H}$ & No & Laparotomy & $\begin{array}{l}\text { Ovarian wedge } \\
\text { resection }\end{array}$ & GnRH & No \\
\hline 58 & $\begin{array}{l}\text { Muneyyirci-Delale et al., } \\
1998[60]\end{array}$ & 35 & AFR & 1 & Dysm & 266 & 3000 & $\mathrm{H}$ & No & Laparotomy & $\begin{array}{l}\text { Adnexal mass } \\
\text { resection }\end{array}$ & $\begin{array}{l}\text { GnRH for } 6 \text { months, then } \\
\text { norethindrone acetate }\end{array}$ & No \\
\hline 59 & Mejia et al., 1997 [61] & 44 & AFR & 0 & Distension & $<35$ & 10000 & $\mathrm{H}$ & No & Laparotomy & TAHBSO & None & No \\
\hline 60 & $\begin{array}{l}\text { Flanagan and Barnes, } \\
1996[62]\end{array}$ & 30 & AFR & & Distension & 49 & 2000 & B & Yes & Laparotomy & $\begin{array}{l}\text { USO, ovarian } \\
\text { wedge } \\
\text { resection }\end{array}$ & GnRH & Yes \\
\hline 61 & el-Newihi et al., 1995 [63] & 32 & AFR & 0 & Distension & 118 & 4000 & B & Yes & Laparotomy & TAHBSO & GnRH IM monthly for 6 months & No \\
\hline 62 & $\begin{array}{l}\text { Schlueter and } \\
\text { McClennan, } 1994 \text { [64] }\end{array}$ & 20 & AFR & 0 & Distension & & 5000 & $\mathrm{H}$ & No & Laparoscopy & Biopsy & GnRH monthly & No \\
\hline 63 & Jose et al., 1994 [65] & 30 & & 0 & Distension & & 5000 & B & Yes & Laparotomy & uso & Danazol $200 \mathrm{mg}$ TID & No \\
\hline 64 & $\begin{array}{l}\text { London and Parmley, } \\
1993[66]\end{array}$ & 29 & AFR & 0 & Distension & & 3000 & B & No & Laparotomy & TAHBSO & None & No \\
\hline 65 & Chen et al., $1992[67]$ & 20 & A & 0 & Distension & 46 & 5600 & B & Yes & Laparotomy & uso & $\begin{array}{l}\text { Danazol } 400 \mathrm{mg} \text { PO daily + } \\
\text { Duphaston } 10 \mathrm{mg} \text { PO OD for } 6 \\
\text { months }\end{array}$ & No \\
\hline 66 & Tsvelev et al., $1990[68]$ & 31 & & & Pain & & 8000 & B & No & Laparotomy & uso & NR & No \\
\hline 67 & Yu and Grimes, 1991 [69] & 26 & A & 0 & Pain & & 3000 & $\mathrm{H}$ & Yes & Laparotomy & uso & GnRH for 6 months & No \\
\hline 68 & Hattori et al., 1990 [70] & 50 & A & 2 & Distension & 36 & 3800 & B & No & Laparotomy & TAHBSO & MPA & Yes \\
\hline 69 & Taub et al., $1989[6]$ & 32 & AFR & 1 & Distension & & 3400 & $\mathrm{H}$ & Yes & Laparotomy & BSO & DMPA & No \\
\hline 70 & Olubuyide et al., 1988 [71] & 19 & AFR & 0 & Distension & & 4600 & $\mathrm{H}$ & No & Laparotomy & Biopsy & $\begin{array}{l}\text { Norethisterone acetate } 5 \mathrm{mg} \text { PO } \\
\text { TID for } 1 \text { week, then } 10 \mathrm{mg} \text { BID }\end{array}$ & No \\
\hline 71 & $\begin{array}{l}\text { Chichareon and } \\
\text { Wattanakitkrailert, } 1988 \\
{[72]}\end{array}$ & 31 & & 0 & Distension & & 1800 & $\mathrm{H}$ & No & Laparotomy & TAHUSO & DMPA & Yes \\
\hline 72 & Iwasaka et al., $1985[73]$ & 35 & A & 0 & Distension & 17 & 2500 & B & No & Laparotomy & TAHBSO & None & No \\
\hline 73 & Iwasaka et al., $1985[73]$ & 25 & A & 0 & Pain & & 150 & $\mathrm{H}$ & No & Laparotomy & $\begin{array}{l}\text { USO, Ovarian } \\
\text { wedge } \\
\text { resection }\end{array}$ & $\begin{array}{l}\text { Danazol } 400 \mathrm{mg} \text { PO daily for } 3 \\
\text { months }\end{array}$ & No \\
\hline 74 & Naraynsingh et al., 1985 & 24 & AFR & 0 & Distension & & 000 & $\mathrm{H}$ & No & Laparotomy & Biopsy & DMPA IM q2 weeks for 6 months & No \\
\hline 75 & Halme et al., $1985[75]$ & 23 & AFR & 0 & Distension & & 7500 & ss & No & Laparotomy & Biopsy & Danazol $400 \mathrm{mg}$ PO BID & No \\
\hline 76 & Jenks et al., 1984 [76] & 33 & AFR & 0 & Distension & & 5000 & $\mathrm{H}$ & No & Laparotomy & TAHBSO & None & No \\
\hline 77 & Gaulier et al., $1983[77]$ & 22 & AFR & 0 & Pain & & $\geq 2000$ & B & Yes & Laparotomy & $\begin{array}{l}\text { Ovarian } \\
\text { resection }\end{array}$ & Danazol & No \\
\hline 78 & $\begin{array}{l}\text { Chervenak et al., } 1981 \\
\text { [78] }\end{array}$ & 20 & & 0 & Distension & & 1500 & B & No & Laparotomy & Bso & None & No \\
\hline 79 & $\begin{array}{l}\text { Chervenak et al., } 1981 \\
\text { [78] }\end{array}$ & 26 & AFR & 0 & Distension & & 4000 & B & No & Laparotomy & BSO & $\begin{array}{l}\text { Danazol } 400 \mathrm{mg} \text { daily for } 10 \\
\text { months }\end{array}$ & No \\
\hline 80 & Irani et al., $1976[79]$ & 32 & AFR & 0 & Distension & & 2000 & $\mathrm{H}$ & Yes & Laparotomy & TAHBSO & None & No \\
\hline 81 & Collier et al., 1962 [80] & 34 & AFR & 0 & Distension & & 4000 & B & No & Laparotomy & TAHBSO & None & Yes \\
\hline 82 & Bernstein et al., 1961 [81] & 29 & AFR & 1 & Distension & & 3900 & B & No & Laparotomy & TAHBSO & None & No \\
\hline
\end{tabular}




\section{Cureus}

\begin{tabular}{|c|c|c|c|c|c|c|c|c|c|c|c|c|}
\hline 83 & Ripstein et al., 1959 [82] & 24 & AFR & 0 & $\begin{array}{l}\text { Chest } \\
\text { discomfort }\end{array}$ & $100-150$ & B & Yes & Laparotomy & Biopsy & $\operatorname{coc}$ & No \\
\hline 84 & Charles, 1957 [2] & 33 & & 0 & Pain & 3000 & H & Yes & Laparotomy & uso & Deep X-ray therapy & Yes \\
\hline
\end{tabular}

\section{TABLE 1: Case reports of endometriosis-related hemorrhagic ascites}

A: Asian; AFR: of African descent; B: brown/dark brown/brownish/chocolate-colored; BS: bilateral salpingectomy; BSO: bilateral salpingooophorectomy; C: Caucasian; COC: combined oral contraceptive pills; coffee: coffee-colored; distension: abdominal distension; DMPA: depot medroxyprogesterone acetate; Dysm: dysmenorrhea; GnRH: gonadotropin-releasing hormone agonists; H: hemorrhagic/bloody; mass: abdominal mass; MPA: medroxyprogesterone acetate; pain: abdominal pain; SS: serosanguinous/blood-stained/haemoserous; TAHBSO: total abdominal hysterectomy with bilateral salpingo-oophorectomy; USO: unilateral salpingo-oophorectomy; RSO: right salpingo-oophorectomy

Patient characteristics are shown in Table 2. The mean age of the patients at diagnosis was 31.16 years (SD: 6.57; range: 19-50). There was no relationship between the year of publication/presentation and age $(\mathrm{p}=0.193)$ or age distribution $(\mathrm{p}=0.600)$.

\begin{tabular}{|l|l|}
\hline Characteristics & Values \\
\hline Age, years, mean (SD) & $31.16(6.57)$ \\
Age range, years & $19-50$ \\
Age distribution, number (\%), N=82 & \\
$<20$ years & $1(1.22)$ \\
$20-29$ years & $31(37.80)$ \\
$30-39$ years & $40(48.78)$ \\
$40-49$ years & $9(10.98)$ \\
$\geq 50$ years & $1(1.22)$ \\
Parity, number (\%), N=78 & \\
Nulliparous & $65(83.33)$ \\
Parous & $13(16.67)$ \\
Race distribution, number (\%), $\mathrm{n}=62$ & \\
African & $43(69.35)$ \\
Asian & $10(16.13)$ \\
Caucasian & $9(14.52)$ \\
Ascitic fluid volume, mL, mean (SD) & $4228.27(2625.66)$ \\
\hline
\end{tabular}

\section{TABLE 2: Endometriosis-related hemorrhagic ascites - patient characteristics}

SD: standard deviation

The most common presenting symptom was abdominal distension (Table 1). Other initial complaints reported by patients are presented in Table 3 . The majority $(91.67 \%, 77 / 84)$ of the symptoms were gradual in onset. Pleural effusion was reported in $32.14 \%$ (27/84) of cases. The ascitic fluid was predominantly massive with a mean volume of $4228.27 \mathrm{~mL}$ (SD: 2625.66; range: 100-10000). CA-125 was elevated in 32 out of 43 patients, with a median value of $86 \mathrm{U} / \mathrm{mL}$ (range: $17->10000 \mathrm{U} / \mathrm{mL}$ ). 


\section{Cureus}

Symptom

Abdominal distension

Dysmenorrhea

Abdominal pain

Weight loss

Primary infertility

Nausea and/or vomiting

Anorexia

Dyspnea

Deep dyspareunia

Fatigue/malaise

Chronic pelvic pain

Constipation

Shortness of breath

Early satiety

Cough

Dyschezia

Menorrhagia

Right-sided chest discomfort

Weight gain

Loose stools

Dysuria

Orthopnea

Abdominal mass

Thoracic pain
Number (\%)

66 (78.57)

47 (55.95)

28 (33.33)

$18(21.43)$

17 (20.24)

$13(15.48)$

11 (13.10)

9 (10.71)

6 (7.14)

6 (7.14)

5 (5.95)

5 (5.95)

4 (4.76)

4 (4.76)

3 (4.57)

3 (3.57)

3 (3.57)

$3(3.57)$

2 (2.38)

2 (2.38)

2 (2.38)

1 (1.19)

1 (1.19)

1 (1.19)

TABLE 3: Symptoms of hemorrhagic ascites associated with endometriosis $(\mathrm{N}=84)$

Moderate to severe endometriosis (ASRM stage III to IV) was seen in 97.44\% (76/78) of the cases, and adhesions were described in $78.05 \%$ (64/82). In $43.90 \%$ (36/82) of the cases, an ovarian cyst was identified; $11.11 \%(4 / 36)$ of the cases were ruptured. Peritoneal implants scattered about the abdominopelvic cavity in $42.68 \%$ (35/82), while peritoneal nodules were seen in 20/82 (24.39\%). Other abdominopelvic areas involved are shown in Table 4. 


\section{Cureus}

\begin{tabular}{|l|l|}
\hline Organ involved & Number (\%) \\
\hline Intestines & $52(63.41)$ \\
\hline Recto-sigmoid & $27(32.93)$ \\
Omentum (caking/nodule/retraction/implants) & $25(30.49)$ \\
Cul-de-sac & $23(28.05)$ \\
Liver & $10(12.20)$ \\
Diaphragm & $7(8.54)$ \\
Appendix & $6(7.32)$ \\
Rectovaginal area & $5(6.10)$ \\
Umbilicus (nodule/mass/cyst) & $4(4.88)$ \\
\hline
\end{tabular}

TABLE 4: Peritoneal involvement in endometriosis-related hemorrhagic ascites $(\mathrm{N}=82)$

At the time of presentation, 64.29\% (54/84) underwent laparotomy, and laparoscopy was performed in $33.33 \%$ (28/84). Two cases (2/84) had paracentesis. Almost half $(44.05 \%, 37 / 84)$ of the cases had repeat abdominal surgeries, while $76.19 \%$ (64/84) required multiple procedures that included repeat abdominal surgeries (laparoscopy and/or laparotomy), paracentesis, thoracostomy, or thoracotomy. On the other hand, less invasive surgical approaches $(\mathrm{p}<0.001)$ and fertility-sparing procedures $(\mathrm{p}<0.001)$ are observed to be increasingly favored in recent years.

A cure was reported in $95.45 \%(21 / 22)$ who went through definitive surgery via hysterectomy with bilateral salpingo-oophorectomy. Medical treatment was not given to $68.18 \%(15 / 22)$ after surgery. Four patients tolerated stripping or excision of the peritoneum of all endometriotic implants with no recurrence. Two of these received no additional medical therapy.

Patients who were offered medical therapy post-surgery received gonadotropin-releasing hormone $(\mathrm{GnRH})$ agonists $(63.79 \%, 37 / 58)$, either alone, with add-back therapy, or as a preliminary treatment that was eventually transitioned to either a progestogen or a combined oral contraceptive (COC) pill. In $86.49 \%$ (32/37) who received GnRH agonists, no recurrences were observed. Other therapies included danazol (13.79\%, 8/58), progestogens alone (10.34\%, 6/58), or COC alone $(10.34 \%, 6 / 58)$. The cure rate with danazol was $100 \%$ (eight out of eight), while COC and progestogens were equally effective, each with an $83.33 \%$ (five out of six) cure rate.

The recurrence rate observed at the time of presentation or after initial management was 36.90\% (31/84), while that after definitive surgery and/or ovarian function suppression was $8.33 \%$ (7/84). Five of these cases reported significant ascites upon the cessation of $\mathrm{GnRH}$ therapy $[35,49,50,62]$ or upon shifting from $\mathrm{GnRH}$ to progestogen therapy [15]. The other two had reaccumulating minimal ascites while on oral COC [35] or oral progestogen [70]. Of note, $71.42 \%$ (five out of seven) of recurrences had undergone ovary-preserving procedures (oophorocystectomy or biopsy) prior to medical therapy. Mortality was reported in one case. The Median follow-up period was eight months.

\section{Analysis}

Very little is known about the pathogenesis of endometriosis-related hemorrhagic ascites. One putative mechanism is peritoneal irritation from the rupture of ovarian cysts. The endometrial cells from this spillage propagate the spread of implants in the pelvic cavity and cause inflammation, which in turn leads to adhesions and ascites [81]. This theory assumes the presence of ovarian cysts. However, in this review, less than half of the study population were found to have ovarian endometriotic cysts, and only four out of 36 of these cysts were ruptured. Alternative hypotheses such as alterations in vascular permeability, lymphatic channel obstruction, as well as individual variations in susceptibility to the disease may be explored $[44,49,83,84]$.

The rubor of ascites may be due to increased angiogenesis seen in endometriosis. Erosions from affected friable soft tissue, serosal, peritoneal surfaces, and implants cause micro-bleeding or frank bleeding, leading to the hemorrhagic character of ascites $[49,84]$. Pleural effusions associated with the hemorrhagic ascites may be due to several mechanisms. However, based on the presentation of massive ascites in the majority of cases, the most plausible cause is anatomic defects in the diaphragm that allow for the passage of hemorrhagic fluid into the pleural space $[85,86]$. 
Endometriosis-related hemorrhagic ascites may affect any woman of reproductive age but is more common in women in their twenties and thirties, without any significant increase or decrease with respect to the age of onset. This finding differs from what was previously described [44]. Many patients may seek a consult for abdominal distension or symptoms secondary to abdominal distension such as pain or pulmonary discomfort in the background of dysmenorrhea or worsening dysmenorrhea. Dysmenorrhea accounted for only 5.95\% $(5 / 84)$ of the chief complaints in this review but is most commonly elicited on history as an accompanying symptom. Massive ascites usually predominate in clinical evaluation.

The utility of CA-125 in the diagnosis of this condition is arguable due to its non-specificity. While the majority presented with CA-125 >35 U/mL, similarly increased levels have been described in various benign gynecologic diseases [87]. Mesothelial cells that line the peritoneum secrete CA-125. Since mesothelial hyperplasia and hypertrophy are associated with endometriosis, CA-125 release is greater, and hence elevated in this condition. However, the same holds true for other diseases of the peritoneum such as malignancy and tuberculosis $[84,88,89]$. Its clinical use, therefore, is limited to determining whether a patient has peritoneal disease in general.

Management of the condition relies critically on establishing a histologic diagnosis. Surgery is thus warranted, although several studies have achieved cytological confirmation through paracentesis [32,51]. With the case presented, a clinically presumptive diagnosis of ovarian cancer was made, which led to the decision to perform a laparotomy. This is supported by studies on ovarian cancer [90]. However, with the availability of minimally invasive techniques and increasing technical confidence among surgeons, there is a growing trend favoring their use in the management of potentially malignant ovarian tumors [90,91]. The current recommendation for laparoscopy in suspected ovarian tumors is to establish a histologic diagnosis through a frozen section and, if tumors are found malignant, to assess their resectability [91-93]. Since it is difficult to differentiate it from a malignant etiology, surgical management of endometriosis-related hemorrhagic ascites may follow this approach.

Moderate to severe (ASRM stage III to IV) endometriosis almost always presents intraoperatively and with adhesions and implants in the abdominopelvic cavity. Peritoneal involvement can be related to small implants, nodules, or varying degrees of adhesions. Thus, the presence of hemorrhagic ascites, as seen in 97.44\% of cases and in the index case, may correlate with the severity of endometriosis.

Since the ascites in this review was found mostly in moderate to severe endometriosis, it seems logical to follow the principles of endometriosis treatment. Termination or suppression of ovarian function is the cornerstone of management. The importance of this cannot be overemphasized as many women undergo multiple surgeries for recurrence or for the treatment of an existing endometriosis. Surgical sterility via hysterectomy with removal of bilateral ovaries is the definitive form of management $[19,3659,61,63,68]$. However, fertility-sparing surgeries are currently performed in patients who wish to realize their reproductive potential.

Medical therapy consists of GnRH agonists, which have been used with success in achieving ovarian suppression. Danazol, progestogens, and COC pills are likewise given as primary treatment or upon completion of GnRH agonist therapy for long-term control of the disease. Danazol, an antigonadotropic, anti-estrogenic synthetic steroid, is effective in suppressing ovarian function. However, its various androgenic effects preclude its use [94,95]. In the majority of cases and especially in more recent studies, GnRH agonists have been used more frequently. These are effective in achieving ovarian suppression and increasing fertility rates but their side effect profile limits their long-term use [94,95]. Progestogens and COC pills were effective as medical treatments in this review, but current evidence has failed to demonstrate any benefit of COC in managing pelvic pain in endometriosis [96]. On the other hand, oral medroxyprogesterone acetate has been shown to be effective in decreasing chronic pelvic pain [97]. Other medications of interest are the levonorgestrel-releasing intrauterine system and mifepristone, which were not used in the studies included in this review. Nonetheless, their clinical utility may be explored as these have been shown to be effective in suppressing the menstrual cycles and relieving pain associated with endometriosis $[98,99]$.

\section{Conclusions}

Hemorrhagic ascites is a rare manifestation of endometriosis that can present in any premenopausal woman. The most common initial complaint is abdominal distension, but a host of other symptoms may also be associated with the condition. Diagnosis can be challenging because it mimics several disease entities that cause ascites, thus warranting a heightened clinical suspicion. Minimally invasive techniques may be employed to establish a histologic diagnosis. Recognition of hemorrhagic ascites as a manifestation of severe endometriosis is essential for recurrence prevention, which should prompt therapies directed at suppressing ovarian function. Ovary-preserving surgeries are preferred because affected women are of childbearing age. Recurrence is low after appropriate surgical and medical interventions.

\section{Additional Information \\ Disclosures}


Human subjects: Consent was obtained or waived by all participants in this study. Taipei Veterans General Hospital Institutional Review Board issued approval VGH IRB: 201710 012AC. This study has been approved by the Taipei Veterans General Hospital Institutional Review Board. Conflicts of interest: In compliance with the ICMJE uniform disclosure form, all authors declare the following: Payment/services info: All authors have declared that no financial support was received from any organization for the submitted work. Financial relationships: All authors have declared that they have no financial relationships at present or within the previous three years with any organizations that might have an interest in the submitted work. Other relationships: All authors have declared that there are no other relationships or activities that could appear to have influenced the submitted work.

\section{Acknowledgements}

Access to databases and procurement of journal article copies were made possible through the Taipei Veterans General Hospital Medical Library, the University of Maryland Medical Center Midtown Campus Medical Staff Library, and Dr. Howard H. Lee. Assistance for the translation of foreign articles was provided by Mr. Andre Anton A. Altea and Dr. Maria Patricia Medina-Kiziler. Many thanks to the various authors of the included studies and to those whose correspondences proved valuable in the creation of this paper.

\section{References}

1. Brews A: Endometriosis including endometriosis of the diaphragm and Meigs' syndrome . Proc R Soc Med. 1954, 47:461.

2. Charles D: Endometriosis and hemorrhagic pleural effusion. Obstet Gynecol. 1957, 10:309-12.

3. Goumenou A, Matalliotakis I, Mahutte N, Koumantakis E: Endometriosis mimicking advanced ovarian cancer. Fertil Steril. 2006, 86:219. 10.1016/j.fertnstert.2005.12.044

4. Myers TJ, Arena B, Granai CO: Pelvic endometriosis mimicking advanced ovarian cancer: presentation with pleural effusion, ascites, and elevated serum CA 125 level. Am J Obstet Gynecol. 1995, 173:966-7. 10.1016/0002-9378(95)90381-x

5. Urrunaga NH, Singal AG, Cuthbert JA, Rockey DC: Hemorrhagic ascites. Clinical presentation and outcomes in patients with cirrhosis. J Hepatol. 2013, 58:1113-8. 10.1016/j.jhep.2013.01.015

6. Taub WH, Rosado S, Kalaycioglu M, Booher D, Barnes DS: Hemorrhagic ascites secondary to endometriosis. J Clin Gastroenterol. 1989, 11:458-60. 10.1097/00004836-198908000-00023

7. Goldberg BB, Goodman GA, Clearfield HR: Evaluation of ascites by ultrasound . Radiology. 1970, 96:15-22. 10.1148/96.1.15

8. Moore KP, Wong F, Gines P, et al.: The management of ascites in cirrhosis: report on the consensus conference of the International Ascites Club. Hepatology. 2003, 38:258-66. 10.1053/jhep.2003.50315

9. Moore CM, Van Thiel DH: Cirrhotic ascites review: pathophysiology, diagnosis and management. World J Hepatol. 2013, 5:251-63. 10.4254/wih.v5.i5.251

10. No authors listed: Revised American Society for Reproductive Medicine classification of endometriosis: 1996. Fertil Steril. 1997, 67:817-21. 10.1016/s0015-0282(97)81391-x

11. Moola S, Munn Z, Tufanaru C, et al.: Systematic reviews of etiology and risk. JBI Manual for Evidence Synthesis. Aromataris E, Munn Z (ed): The Joanna Briggs Institute, Adelaide, Australia; 2017. 1:20-30. 10.46658/JBIMES-20-08

12. Page MJ, McKenzie JE, Bossuyt PM, et al.: The PRISMA 2020 statement: an updated guideline for reporting systematic reviews. BMJ. 2021, 372:n71. 10.1136/bmj.n71

13. Soyman Z, Bacanakgil BH, Kaya S, et al.: An uncommon presentation of endometriosis a case report . J Reprod Med. 2018, 63:317-8.

14. Mendes S, Carvalho C, Rodrigues G, Barata S, Calhaz-Jorge C, Osório F: Successful treatment of endometriosis-related hemorrhagic ascites: a report of three cases. Surg Technol Int. 2018, 32:150-5.

15. Walker PJ, Johnson NP: Benign endometriosis masquerading as intra-abdominal malignancy: one of the most extreme cases reported and a review of the literature. J Endometr Pelvic Pain Disord. 2018, 10:174-7. $10.1177 / 2284026518780820$

16. O’yandjo AM, Bosenge NJD, Kadima NJ: Umbilical nodule and hemorrhagic ascites of endometriosis origin: a clinical case report. Gynecol Obstet Case Rep. 2018, 4:62. 10.21767/2471-8165.1000062

17. Magalhães TF, Augusto KL, Mota LP, Costa ARD, Puster RA, Bezerra LRPS: Ascites and encapsulating peritonitis in endometriosis: a systematic review with a case report. Rev Bras Ginecol Obstet. 2018, 40:14755. 10.1055/s-0038-1626700

18. Petrosellini C, Abdalla S, Oke T: The many guises of endometriosis: giant abdominal wall endometriosis masquerading as an incisional hernia. Int J Fertil Steril. 2018, 11:321-5. 10.22074/ijfs.2018.5126

19. Pereira N, Gunnala V, Palermo GD, Elias RT: Laparoscopic management of severe endometriosis-related hemorrhagic ascites. J Minim Invasive Gynecol. 2018, 25:8-9. 10.1016/j.jmig.2017.03.010

20. N'Guessan E, Kouamé N, Dia JM, Gbeli F, Guié P, Anongba S: Endometriosis revealed by recurrent hemorrhagic ascites. Open J Obstet Gynecol. 2017, 7:1160-5. 10.4236/ojog.2017.712117

21. Varun N, Tanwar RT: A rare presentation of endometriosis with massive haemorrhagic ascites: a case report . Gynecol Obstet Case Rep. 2016, 3:1. 10.21767/2471-8165.1000047

22. Dun EC, Wong S, Lakhi NA, Nehzat CH: Recurrent massive ascites due to mossy endometriosis . Fertil Steril. 2016, 106:e14. 10.1016/j.fertnstert.2016.07.1119

23. Hinduja I, Kapadia K, Udwadia F, Bhilawadikar R, Adhe A, Zaveri K: Unusual presentation of endometriosis with haemorrhagic ascites - a case report. J Obstet Gynaecol. 2016, 36:133-4. 10.3109/01443615.2015.1030605

24. Setubal A, Sidiropoulou Z, Soares S, Barbosa C: Endometriosis and ascites: a strategy to achieve pregnancy . J Minim Invasive Gynecol. 2015, 22:1104-8. 10.1016/j.jmig.2015.05.013

25. Bignall J, Arambage K, Vimplis S: Endometriosis: a rare and interesting cause of recurrent haemorrhagic 
ascites. BMJ Case Rep. 2014, 2014:bcr2013010052. 10.1136/bcr-2013-010052

26. Cosma S, Ceccaroni M, Benedetto C: A pseudoneoplastic finding of deep endometriosis: laparoscopic triple segmental bowel resection. Wideochir Inne Tech Maloinwazyjne. 2014, 9:463-7. 10.5114/wiitm.2014.41617

27. Hasdemir PS, Ikiz N, Ozcakir HT, Kara E, Guvenal T: Endometriosis associated with relapsing ascites and pleural effusions. J Obstet Gynaecol. 2015, 35:419. 10.3109/01443615.2014.948823

28. Park CM, Kim SY: Rupture of an endometrioma with extremely high serum CA-125 level (> 10,000 IU/ml) and ascites resembling ovarian cancer. Eur J Gynaecol Oncol. 2014, 35:469-72.

29. Asano R, Nakazawa T, Hirahara F, Sakakibara H: Dienogest was effective in treating hemorrhagic ascites caused by endometriosis: a case report. J Minim Invasive Gynecol. 2014, 21:1110-2. 10.1016/j.jmig.2014.04.014

30. Appleby R, Saroya H, Postgate A, Meer Z: A young woman with abdominal distension . BMJ Case Rep. 2014, 2014:bcr2014203726. 10.1136/bcr-2014-203726

31. Mumtahana F, Jiao J, Cui B: A rare presentation of endometriosis with recurrent massive hemorrhagic ascites which can mislead. Int J Women's Health Reproduction Sci. 2014, 2:30-4. 10.15296/ijwhr.2014.05

32. Packard LK, Adamson GD: Endometriosis presenting with massive ascites and pleural effusion: a case report. J Endometr Pelvic Pain Disord. 2013, 5:123-5. 10.5301/je.5000162

33. Akinola RA, Akinola OI, Alakija A, Wright KO: Widespread endometriosis mimicking ovarian malignancy: a case report. Niger Postgrad Med J. 2012, 19:46-9.

34. Akintomide AO, Bassey DB, Ekanem EI, Omotosho AJ: Omental endometriosis: a rare site and an unusual association with ovarian fibroma and haemorrhagic ascites. A case report and review of the imaging techniques. IOSR JDMS. 2012, 2:22-6. 10.9790/0853-0212226

35. Queirós A, Correia L, Pinto G, Rosa D, Silva G, Simões T: Endometriosis with hemorrhagic ascites: two cases report (Article in Portuguese). Rev Iberoam Fert Rep Hum. 2011, 28:141-5.

36. Shabeerali TU, Rajan R, Kuruvilla AP, et al.: Hemorrhagic ascites: are we missing endometriosis? . Indian J Gastroenterol. 2012, 31:195-7. 10.1007/s12664-012-0221-1

37. Ferrero S, Remorgida V: Endometriosis presenting with hemorrhagic ascites. Arch Gynecol Obstet. 2011, 283:1429-30. 10.1007/s00404-010-1796-3

38. Cordeiro Fernandes LF, Podgaec S, Castro Cotti GC, Abrao MS: Severe endometriosis may be considered in the differential diagnosis in young women presenting massive hemorrhagic ascites. Gynecol Surg. 2011, 8:459. 10.1007/s10397-011-0690-8

39. Suchetha S, Rema P, Mathew AP, Sebastian P: Endometriosis with massive hemorrhagic ascites. Indian J Cancer. 2010, 47:224-5. 10.4103/0019-509X.63004

40. Ignacio MM, Joseph N, Hélder F, Mamourou K, Arnaud W: Massive ascites, pleural effusion, and diaphragmatic implants in a patient with endometriosis. Eur J Obstet Gynecol Reprod Biol. 2010, 149:117-8. 10.1016/j.ejogrb.2009.10.017

41. Day T, Hui K, Perkins S, Pelletier P: Ascites and ileus due to endometriosis. J Pelvic Med Surg. 2009, 15:4715. 10.1097/SPV.0b013e3181c6e90b

42. Park BJ, Kim TE, Kim YW: Massive peritoneal fluid and markedly elevated serum CA125 and CA19-9 levels associated with an ovarian endometrioma. J Obstet Gynaecol Res. 2009, 35:935-9. 10.1111/j.14470756.2009.01122.x

43. Lodha A, Klein T, Elish D, Tarkovsky R: Endometriosis: a rare presentation as hemorrhagic ascites . Pract Gastroenterol. 2008, 32:48-9.

44. Ussia A, Betsas G, Corona R, De Cicco C, Koninckx PR: Pathophysiology of cyclic hemorrhagic ascites and endometriosis. J Minim Invasive Gynecol. 2008, 15:677-81. 10.1016/j.jmig.2008.08.012

45. Sait KH: Massive ascites as a presentation in a young woman with endometriosis: a case report . Fertil Steril. 2008, 90:2015. 10.1016/j.fertnstert.2008.07.021

46. Santos VM, Barbosa ER Jr, Lima SH, Porto AS: Abdominal cocoon associated with endometriosis. Singapore Med J. 2007, 48:e240-2.

47. Palayekar M, Jenci J, Carlson JA Jr: Recurrent hemorrhagic ascites: a rare presentation of endometriosis . Obstet Gynecol. 2007, 110:521-2. 10.1097/01.AOG.0000268283.99315.58

48. Baykal C, Arioglu P, Kalayci M, Özkan F, Çetinkaya N, Fiçicioglu C: Giant endometrioma mimicking ovarian carcinoma: case report. Turk J Obstet Gynecol. 2006, 3:356-8.

49. Ekoukou D, Guilherme R, Desligneres S, Rotten D: Endometriosis with massive hemorrhagic ascites: a case report and review of the literature (Article in French). J Gynecol Obstet Biol Reprod (Paris). 2005, 34:351-9. 10.1016/s0368-2315(05)82841-8

50. Fortier D, Dedecker F, Gabriele M, Graesslin O, Barau G: Endometriosis with ascites and pleural effusion: a case report (Article in French). Gynecol Obstet Fertil. 2005, 33:508-10. 10.1016/j.gyobfe.2005.05.014

51. Zeppa P, Vetrani A, Cozzolino I, Palombini L: Endometrial glands in ascites secondary to endometriosis . Diagn Cytopathol. 2004, 30:131-2. 10.1002/dc.10390

52. Francis M, Badero OO, Borowsky M, Lee YC, Abulafia O: Pericardial effusion, right-sided pleural effusion and ascites associated with stage IV endometriosis. A case report. J Reprod Med. 2003, 48:463-5.

53. Cheong EC, Lim DT: Massive ascites--an uncommon presentation of endometriosis . Singapore Med J. 2003, 44:98-100.

54. Moffatt SD, Mitchell JD: Massive pleural endometriosis. Eur J Cardiothorac Surg. 2002, 22:321-3. 10.1016/s1010-7940(02)00277-4

55. Dias CC, Andrade JM, Ferriani RA, Villanova MG, Meirelles RS: Hemorrhagic ascites associated with endometriosis. A case report. J Reprod Med. 2000, 45:688-90.

56. Bhojawala J, Heller DS, Cracchiolo B, Sama J: Endometriosis presenting as bloody pleural effusion and ascites-report of a case and review of the literature. Arch Gynecol Obstet. 2000, 264:39-41. 10.1007/p100007484

57. El Khalil T, Mourad FH, Barada K, Uthman S: Massive hemorrhagic ascites secondary to endometriosis. J Clin Gastroenterol. 1999, 29:344-5. 10.1097/00004836-199912000-00010

58. Samora-Mata J, Feste JR: Endometriosis ascites: a case report. JSLS. 1999, 3:229-31.

59. Fletcher H, McFarlane M, Shirley SE, Clarke WF, Lyon K: Massive ascites secondary to severe endometriosis. 
West Indian Med J. 1999, 48:158-9.

60. Muneyyirci-Delale O, Neil G, Serur E, Gordon D, Maiman M, Sedlis A: Endometriosis with massive ascites . Gynecol Oncol. 1998, 69:42-6. 10.1006/gyno.1998.4953

61. Mejia EM, Alvarez OA, Lee M: Endometriosis with massive bloody ascites. J Am Board Fam Pract. 1997, 10:59-61.

62. Flanagan KL, Barnes NC: Pleural fluid accumulation due to intra-abdominal endometriosis: a case report and review of the literature. Thorax. 1996, 51:1062-3. 10.1136/thx.51.10.1062

63. el-Newihi HM, Antaki JP, Rajan S, Reynolds TB: Large bloody ascites in association with pelvic endometriosis: case report and literature review. Am J Gastroenterol. 1995, 90:632-4.

64. Schlueter FJ, McClennan BL: Massive ascites and pleural effusions associated with endometriosis . Abdom Imaging. 1994, 19:475-6. 10.1007/BF00206945

65. Jose R, George SS, Seshadri L: Massive ascites associated with endometriosis . Int J Gynaecol Obstet. 1994, 44:287-8. 10.1016/0020-7292(94)90185-6

66. London S, Parmley T: Endometriosis and ascites. South Med J. 1993, 86:1173-5. 10.1097/00007611199310000-00022

67. Chen FF, Chow NH, Chou CY, Lin MF: Hemorrhagic ascites associated with endometriosis: a rare clinical presentation. J Gynecol Surg. 1992, 8:43-7. 10.1089/gyn.1992.8.43

68. Tsvelev IuV, Lishchuk VD, Kolosov AE: Ascites as a manifestation of generalized endometriosis (Article in Russian). Vestn Khir Im I I Grek. 1990, 145:48-50.

69. Yu J, Grimes DA: Ascites and pleural effusions associated with endometriosis . Obstet Gynecol. 1991, 78:5334.

70. Hattori S, Tamakoshi K, Oguchi H, Kodama H: A case of endometriosis with massive ascites (Article in Japanese). Nihon Sanka Fujinka Gakkai Zasshi. 1990, 42:291-4.

71. Olubuyide IO, Adebajo AO, Adeleye JA, Solanke TF: Massive ascites associated with endometriosis in a Nigerian African. Int J Gynaecol Obstet. 1988, 27:439-41. 10.1016/0020-7292(88)90127-0

72. Chichareon SB, Wattanakitkrailert S: Endometriosis with ascites. Acta Obstet Gynecol Scand. 1988, 67:1878. 10.3109/00016348809004198

73. Iwasaka T, Okuma Y, Yoshimura T, Kidera Y, Sugimori H: Endometriosis associated with ascites. Obstet Gynecol. 1985, 66:72S-5.

74. Naraynsingh V, Raju GC, Ratan P, Wong J: Massive ascites due to omental endometriosis . Postgrad Med J. 1985, 61:539-40. 10.1136/pgmj.61.716.539

75. Halme J, Chafe W, Currie JL: Endometriosis with massive ascites. Obstet Gynecol. 1985, 65:591-2.

76. Jenks JE, Artman LE, Hoskins WJ, Miremadi AK: Endometriosis with ascites. Obstet Gynecol. 1984, 63:75S-7.

77. Gaulier A, Jouret-Mourin A, Marsan C: Peritoneal endometriosis. Report of a case with cytologic, cytochemical and histopathologic study. Acta Cytol. 1983, 27:446-9.

78. Chervenak FA, Greenlee RM, Lewenstein L, Tovell HM: Massive ascites associated with endometriosis . Obstet Gynecol. 1981, 57:379-81.

79. Irani S, Atkinson L, Cabaniss C, Danovitch SH: Pleuroperitoneal endometriosis. Obstet Gynecol. 1976, 47:72S-4.

80. Collier HA, Gonzales LL, Bossert LJ: Cyclic ascites as a manifestation of endometriosis. Report of a case . Obstet Gynecol. 1962, 19:681-3.

81. Bernstein JS, Perlow V, Brenner JJ: Massive ascites due to endometriosis . Am J Digest Dis. 1961, 6:1-6. 10.1007/BF02239240

82. Ripstein CB, Robman M, Wallach JB: Endometriosis involving the pleura. J Thorac Surg. 1959, 37:464-71.

83. Koninckx PR, Renaer M, Brosens IA: Origin of peritoneal fluid in women: an ovarian exudation product . Br J Obstet Gynaecol. 1980, 87:177-83. 10.1111/j.1471-0528.1980.tb04514.x

84. Koninckx PR, Kennedy SH, Barlow DH: Pathogenesis of endometriosis: the role of peritoneal fluid. Gynecol Obstet Invest. 1999, 47:23-33. 10.1159/000052856

85. Hwang SM, Lee CW, Lee BS, Park JH: Clinical features of thoracic endometriosis: a single center analysis . Obstet Gynecol Sci. 2015, 58:223-31. 10.5468/ogs.2015.58.3.223

86. Nwiloh J: Diaphragmatic patch: a useful adjunct in surgical treatment of recurrent catamenial hemothorax . Rev Port Pneumol. 2011, 17:278-80. 10.1016/j.rppneu.2011.06.006

87. Daoud E, Bodor G: CA-125 concentrations in malignant and nonmalignant disease . Clin Chem. 1991, 37:1968-74.

88. Chen DX, Schwartz PE, Li XG, Yang Z: Evaluation of CA 125 levels in differentiating malignant from benign tumors in patients with pelvic masses. Obstet Gynecol. 1988, 72:23-7.

89. Oparka R, McCluggage WG, Herrington CS: Peritoneal mesothelial hyperplasia associated with gynaecological disease: a potential diagnostic pitfall that is commonly associated with endometriosis. J Clin Pathol. 2011, 64:313-8. 10.1136/jcp.2010.086074

90. Rimbach S, Neis K, Solomayer E, Ulrich U, Wallwiener D: Current and future status of laparoscopy in gynecologic oncology. Geburtshilfe Frauenheilkd. 2014, 74:852-9. 10.1055/s-0034-1383075

91. Angeles MA, Martínez-Gómez C, Migliorelli F, et al.: Novel surgical strategies in the treatment of gynecological malignancies. Curr Treat Options Oncol. 2018, 19:73. 10.1007/s11864-018-0582-5

92. Ratnavelu ND, Brown AP, Mallett S, et al.: Intraoperative frozen section analysis for the diagnosis of early stage ovarian cancer in suspicious pelvic masses. Cochrane Database Syst Rev. 2016, 3:CD010360. 10.1002/14651858.CD010360.pub2

93. Morton R, Anderson L, Carter J, Pather S, Saidi SA: Intraoperative frozen section of ovarian tumors: a 6-year review of performance and potential pitfalls in an Australian tertiary referral center. Int J Gynecol Cancer. 2017, 27:17-21. 10.1097/IGC.0000000000000851

94. Brown J, Farquhar C: Endometriosis: an overview of Cochrane Reviews . Cochrane Database Syst Rev. 2014, 2014:CD009590. 10.1002/14651858.CD009590.pub2

95. Berlanda N, Somigliana E, Viganò P, Vercellini P: Safety of medical treatments for endometriosis. Expert Opin Drug Saf. 2016, 15:21-30. 10.1517/14740338.2016.1121991

96. Brown J, Crawford TJ, Datta S, Prentice A: Oral contraceptives for pain associated with endometriosis . 


\section{Cureus}

Cochrane Database Syst Rev. 2018, 5:CD001019. 10.1002/14651858.CD001019.pub3

97. Brown J, Kives S, Akhtar M: Progestagens and anti-progestagens for pain associated with endometriosis . Cochrane Database Syst Rev. 2012, 2012:CD002122. 10.1002/14651858.CD002122.pub2

98. Fu J, Song H, Zhou M, Zhu H, Wang Y, Chen H, Huang W: Progesterone receptor modulators for endometriosis. Cochrane Database Syst Rev. 2017, 7:CD009881. 10.1002/14651858.CD009881.pub2

99. Abou-Setta AM, Houston B, Al-Inany HG, Farquhar C: Levonorgestrel-releasing intrauterine device (LNGIUD) for symptomatic endometriosis following surgery. Cochrane Database Syst Rev. 2013, 1:CD005072. 10.1002/14651858.CD005072.pub3 